\title{
Adding support to cross-cultural emotional assessment: Validation of the International Affective Picture System in a Chilean sample*
}

Un apoyo a la evaluación transcultural de la emoción: validación del International Affective Picture System en una muestra chilena

Recibido: agosto 2 de 2009 | Revisado: enero 15 de 2010 | Aceptado: junio 21 de 2010

\author{
MicheLE DUFEY ** \\ Universidad Diego Portales, Santiago, Chile \\ ANA MARÍA FERNÁNDEZ **** \\ Universidad de Santiago de Chile y Universidad \\ Diego Portales, Santiago, Chile \\ ROCÍO MAYOL ${ }^{* * * * *}$ \\ Universidad de Chile
}

SICI: 1657-9267(201108)10:2<521:ASCCEA >2.0.TX;2-B

Para citar este artículo. Dufey, M., Fernández, A. M., Mayol, R. (2011). Adding support to cross-cultural emotional assessment: Validation of the International Affective Picture System in a Chilean sample. Universitas Psychologica, 10 (2), 521-533.

* Artículo de investigación

**Vergara 275, Santiago, Chile. E-maill: mdufey@ gmail.com

Research-ID: Dufey, M., E-1358-2011

**** Avenida Ecuador 3650, tercer piso, Estación Central, Santiago, Chile. E-mail: anamaria09@vtr.net

***** Facultad de Medicina, Av. Independencia 1027, Santiago, Chile. E-mail: rociomayolt@gmail.com
A B S T R A C T

The present study aimed to obtain a valid set of images of the International Affective Picture System (Lang, Bradley \& Cuthbert, 2005) -a widely used instrumentation in emotion research-in a Chilean sample, as well as comparing these results with those obtained from the US study in order to con tribute to its cross-cultural validation. A sample of 135 college students assessed 188 pictures according to standard instructions in valence and arousal dimensions. The results showed the expected organization of affectivity, with variations between sex in valence judgments, and differences between countries in the arousal dimension. It is concluded that the Chilean adaptation of the IAPS is consistent with the previous evidence, adding support to it cross-cultural validity.

Key words authors

Affective Valence, Arousal, Cross-Cultural Differences, Emotional Assessment. Key words plus

Psychological Research, Psychological Tests, Social Behaviour, Interpersonal

Relations, Emotions, Cultural Interaction.

\section{RES U MEN}

El presente estudio tiene como objetivo validar un conjunto de imágenes del International Affective Picture System (IAPS) de Lang, Bradley y Cuthbert (2005) -un instrumento ampliamente utilizado en investigación afectiva - en una muestra chilena, así como comparar sus resultados con aquellos obtenidos en el estudio estadounidense, en vistas a contribuir a su validación intercultural. Se utilizó una muestra de 135 estudiantes universitarios, quienes evaluaron 188 imágenes en las dimensiones de valencia y arousal, de acuerdo con instrucciones estándar. Los resultados muestran la organización esperada de la afectividad, con variaciones entre sexos en la valoración de valencia, y diferencias entre países en la dimensión de arousal. Se concluye que la adaptación chilena del IAPS es consistente con los estudios previos, lo cual añade evidencia a favor de su validez intercultural. Palabras clave autores

Arousal, diferencias interculturales, evaluación afectiva, valencia afectiva. Palabras clave descriptores

Investigación psicológica, test psicológico, comportamiento social, relaciones interpersonales, afectividad, interacción cultural. 


\section{Introduction}

The scientific study of emotions has been an emblematic topic for psychology. In fact, considerable conceptual and methodological challenges have been posed by diverse authors from the beginnings of the discipline to nowadays to uncover the quintessence of emotion. Modern techniques have confirmed and refined what was already stated by pioneers like James, Lange and Wundt: emotions are by definition adaptive body responses that activate the organism in response to environmental stimuli. There is no doubt that with the advent of psychophysiology and neuroscience a deeper understanding of the biological and neurophysiological basis of the emotional phenomenon has been achieved (for example, see Carretie, 2001; Davidson, 2003). At the present time, there is a vast consensus that emotions are action dispositions that have been modeled throughout evolution, with a high degree of phylogenetic conservation (Lang, 1995).

Several authors have argued for the existence of a biphasic structure of affectivity that accounts for two motivational systems: one appetitive and another aversive (Davidson, 2003; Lang, 1995; Lang, Bradley \& Cuthbert, 1990). The first of these systems is responsible for approaching behaviors, attachment and consummatory acts when safety is perceived, whereas the activation of the latter allows withdrawal, escape and defense in threatening situations. Any emotional reaction can be placed in the approach-avoidance continuum and this defines a specific action pattern that is consistent with the underlying state of the central affect-motivational organization. This motivated behavior has an evolutionary basis that has shaped both central (cerebral) and peripheral (somatic and autonomic) components that account for each motivational system, that have been specified by diverse studies with animals (Fanselow, 1994; Kapp, Frysinger, Gallagher \& Haselton, 1979; LeDoux, 1990) and humans (Bradley, Codispoti, Cuthbert \& Lang, 2001a; Bradley, Codispoti, Sabatinelli \& Lang, 2001b; Palomba, Sarlo, Angrilli,
Mini \& Stegagno, 2000; Schupp, Cuthbert, Bradley, Birbaumer \& Lang, 1997).

Based on the revision of diverse theorists of emotions, Bradley and Lang (2007) propose that affective motivational activation can be judged by two dimensions: the hedonic valence that indexes which motivational system is engaged, and the arousal dimension, which expresses its activation degree. Also, they highlight the need to rely on valid and standardized metrics in emotion research, considering the diversity of physical parameters by which the emotional stimuli can be defined and emotional states can be induced, leading to incomparability of results among different studies. Thus, the authors have made an important effort in order to collect and standardize pictures that represent a wide spectrum of experiences linked to human life, which have been arranged in a large database named the International Affective Picture System (IAPS), (Lang, Bradley \& Cuthbert, 2005).

The IAPS pictures depict emotional situations that are rated in valence, arousal and dominance dimensions using the Self-Assessment Manikin (SAM), (Lang, 1980), a 9-point analogue scale, for both men and women. An "affective space" with a boomerang shape appears when the total ratings for each image are plotted according to the valence and arousal dimensions in the $\mathrm{Y}$ and $\mathrm{X}$ axis, respectively. The characteristics of the affective space are consistent with the theoretical organization of affectivity: hedonic ratings become more positive and negative as arousal levels increase, revealing that the amount of arousal reflects the degree of activation in both appetitive and defensive systems. The psychometric properties of the IAPS have been optimal in both reliability and validity (Bradley \& Lang, 2007; Lang, 1995).

Diverse studies have shown the robustness of the primary motivational systems. Electrophysiological results tend to be replicated across studies (e.g. Amrhein, Mülberger, Pauli \& Wiedemann, 2004; Bradley et al., 2001a; see also Olofsson, Nordin, Sequeira \& Polich, 2008, for a detailed event-related potential's review). Standardization reports for the IAPS have been also conducted in 
different countries, such as Brazil, Spain, and the US, as well as validation and adaptation studies in Germany and Belgium. A comparative reading of this evidence shows similarity among methodological aspects, with main variations in the number and extraction procedure of pictures as well as the inclusion, or not, of the dominance dimension of the SAM. This allows relative consistence between studies, thus, a considerable degree of comparability between results.

In the Brazilian validation of the IAPS (Lasaitis, Ribeiro \& Bueno, 2008; Ribeiro, Pompéia \& Bueno, 2004, 2005) results in the valence dimension are equivalent to the US standardization, whereas arousal scores are higher in Brazil. Also, and for the same pictures set, Brazilian students reveal a stronger linear association between valence and arousal $(r=-0.82)$ than the US normative $(r=-0.25)$, which is explained by the authors by the tendency of Brazilians to nominate positive pictures as less arousing. In the German adaptation (Grühn $\&$ Scheibe, 2008) a strong negative correlation between valence and arousal is emphasized $(r=$ -0.79), whereas this association in the US study was smaller $(r=-0.47)$. Although erotic pictures were perceived as more positive and less arousing by the US sample, Spanish results (Moltó et al., 1999; Vila et al., 2001) are comparable in valence to the US study but with lower arousal scores; while the Belgium data (Verschuere, Crombez \& Koster, 2007) shows similar results for both dimensions when compared to the US norm.

In sum, results are consistent across the different standardization and validation studies of the IAPS, pointing to a high conservation in the predicted organization of affectivity. Variations in the association between valence and arousal dimension are observed across some countries, which can be in part due to methodological or conceptual issues related to the understanding of the meaning of the dimensions (e.g., arousal dimension, Ribeiro et al., 2005). Alternatively, differences might be consistent with the observation that the IAPS can be sensitive to detect cultural differences in emotion disposition (Bradley \& Lang, 2005).
The present study was aimed to attain a valid set of the IAPS pictures in a Chilean sample. Also, due to the relevance in obtaining cross-cultural information regarding the validity of affectivity assessment by the IAPS, a comparison between US and Chilean results was made. It was expected that the judgment of the pictures would follow previous findings in the structure of the affective space, and more arousing scores were hypothesized to emerge from negative pictures in relation to positive ones. Some studies have shown that the arousal dimension is sensitive to cultural differences among countries, wherein the IAPS has been validated (i.e. Grühn \& Scheibe, 2008; Ribeiro, Pompéia $\&$ Amodeo, 2004, 2005). Therefore, possible discrepancies in the arousal dimension between the Chilean and the US studies were expected to occur.

\section{Method}

\section{Participants}

A total sample of 135 psychology college students were recruited, with a mean age of 20.13 (SD $=2.29$ ) and from which $65 \%$ were women. All the participants participated voluntarily in the research.

\section{Stimuli}

One hundred and eighty eight colored pictures were selected from the IAPS database. Since this study was part of a broader research, slides were intentionally extracted and picture content was chosen to depict household objects or people in diverse social situations. The picture numbers are presented in Appendix 1

\section{Procedure}

Data collection was carried out during classroom hours in an introductory psychology course. Pictures were assessed by two subsamples of 68 and 67 participants each; the first one rated 105 pictures and, the second one, 83 pictures. In a first step, 
the class instructor agreed to provide 45 minutes approximately for the pictures assessment. Due to time restrictions, groups of participants were conformed according to the number of students attending the class, ranging from 10 to 40 participants per group, with a total number of five groups. The researcher then introduced herself and briefly exposed the aim of the study, as part of a broader research aimed to obtain valid material for laboratory assessment. Voluntary participation was required, allowing anyone who wished to refrain from participating at that moment to leave the classroom. Afterwards, an informed consent was provided and the classroom was arranged in order to optimize the visual access of each participant to the screen of $2 \mathrm{mts}$. $\mathrm{2}$ mts., where images were going to be projected, and booklets with the paper and pencil version of the SAM were distributed among participants. Only valence and arousal dimensions were assessed, as they are major factors that account for the most part of the variance in emotion (Lang, 1995).

In order to adjust the procedure as much as possible to the original protocol of application, a bilingual psychologist translated the English version of instructions to Spanish, and they were literally read in each assessment session. Only the section referred to dominance scale was omitted and application timings were adjusted to the original procedure. The slides presentation was performed with MS Power Point 2000, three example slides were presented (\#4601, \#2222 and \#2799) and any question concerning the procedure to work on the booklets was clarified.

At the beginning of the assessment, pictures were presented in a pseudo-randomized order, with the restriction of no more than two consecutive pictures of the same valence category appearing simultaneously. Before the picture presentation, a warning slide of one second informed the number of pictures that were coming in the next slide, and then each picture was presented for a six-second period followed by a ten-second black screen. At that moment the participants proceeded to give the SAM ratings. Once the picture assessment was completed, booklets were collected and participants were thanked for their collaboration.

Individual scores were coded and analyzed in SPSS 15.0. In order to gain comparability between Chilean and US results, comparisons between both countries considered judgments for the same pictures dataset by participants from both countries.

\section{Results}

\section{Reliability}

Internal consistency was performed on the total number of pictures rated by each participant. Cronbach's alfa was 0.976 for the valence dimension, and 0.979 for the arousal dimension.

\section{Descriptive results}

Table 1 shows the main descriptive statistics obtained for this study, as well as the results of the US standardization in order to facilitate their comparability. Scores for valence dimension in the Chilean sample tended to be lower than the US sample, but no significant difference was obtained, $t(1,368)$ $=-1.212, p=0.227$. However, Chilean scores in the arousal dimension were significantly higher than US scores, $t(1,360.5)=5.342, p=0.000$.

\section{Affective space}

A very similar distribution to the original plot of the affective space in the US was obtained in the Chilean sample, with valence and arousal scores in the vertical and horizontal axis, respectively. The linear regression model between valence and arousal was significant $(r=0.62)$, but a better adjustment was observed for the quadratic function $(r=0.69)$, revealing that at higher amounts of arousal, both positive and negative valence become more robust (see Figure 1). This result was consistent with those observed for the US study, in which linear and quadratic values were $r=0.28$ and 0.54 , respectively. However, the higher linear association between valence and arousal observed 
TABLE 1

Means (and standard deviations) for the selected IAPS pictures in Chile and the US

\begin{tabular}{ccccccccc}
\hline & \multicolumn{9}{c}{ Valence } & \multicolumn{5}{c}{ Arousal } \\
\hline & Pos & Neg & Neu & Total & Pos & Neg & Neu & Total \\
\hline \multirow{2}{*}{ Chile } & 7.04 & 2.47 & 4.91 & 4.70 & 4.88 & 6.64 & 4.09 & 5.28 \\
& $(0.50)$ & $(0.79)$ & $(0.50)$ & $(2.00)$ & $(0.79)$ & $(1.09)$ & $(0.60)$ & $(1.38)$ \\
\multirow{2}{*}{ US } & 6.97 & 2.97 & 5.18 & 4.95 & 4.74 & 5.26 & 3.37 & 4.51 \\
& $(0.84)$ & $(1.10)$ & $(0.64)$ & $(1.90)$ & $(0.93)$ & $(0.92)$ & $(0.83)$ & $(1.20)$ \\
\hline
\end{tabular}

Note. Pos: positives; Neg: negatives; Neu: neutrals.

Source: own work.

in the Chilean sample could be explained for the incremented scores in the arousal dimension, in comparison with the US sample.

Also, the total correlation between valence and arousal in Chile was $r=-0.62, p=0.000$, indicating that higher levels of arousal are related to a more negative perception of the pictures. When compared to the US correlations among dimensions for the same subsample of pictures $(r$ $=-0.23, p=0.001)$, a similar trend is observed among countries.

In order to compare the association between the valence and arousal dimension among Chile and US, a correlation between each dimension for each country was performed. High levels of consis- tency were obtained for both dimensions (valence $r=0.94, p=0.001$; arousal $r=0.78, p=0.001$ ). However, the lower magnitude of the association between Chile and US in the arousal dimension can be explained for the higher scores observed in this dimension for the Chilean sample.

\section{Valence comparisons}

The correlation between valence and arousal was $r$ $=0.36(p=0.001)$ for positive pictures, $r=-0.83$ $(p=0.001)$ for negative pictures and $r=0.13(\mathrm{p}=$ 0.177 ) for neutral pictures. That means that the association between valence and arousal is higher in magnitude for the negative when compared to the

FIGURE 1

Scatterplot of valence and arousal and their correlation in a linear and quadratic model for the Chilean sample

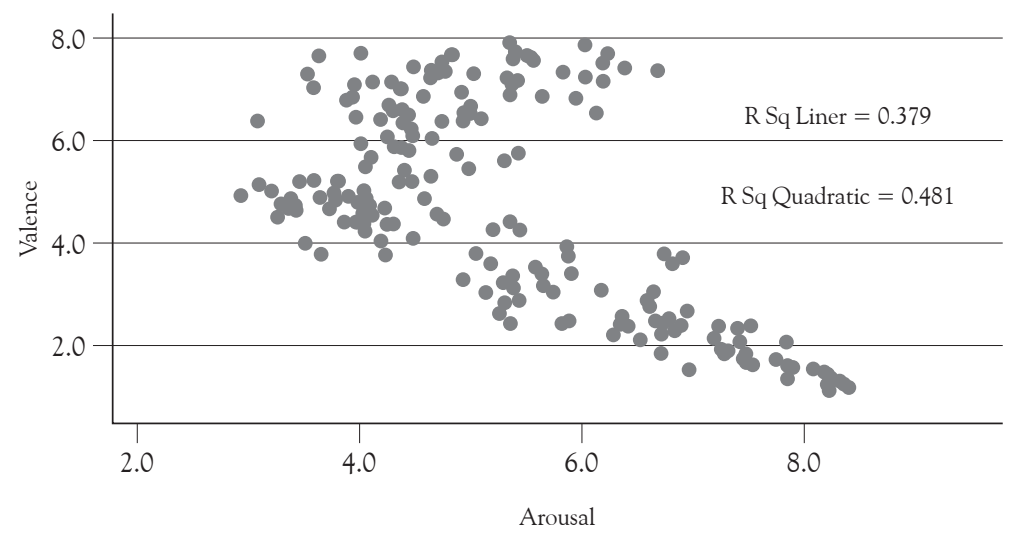

Source: own work. 
positive category, whereas neutral pictures showed no association between dimensions, consistent with the US study results $(r=0.33, p=0.006 ; r$ $=-0.56, p=0.000 ; r=0.07, p=0.596$, for positive, negative and neutral pictures, respectively).

\section{Sex differences}

Figure 2 shows the distribution adopted by the pictures in the affective space according to sex, depicting a very similar shape to the US results (women positive and negative $r=0.20$ and -0.77 ; men $r$
$=0.68$ and -0.55 , respectively). That is, the correlation between valence and arousal was higher for negative pictures when compared to positive pictures; nevertheless, higher scores were observed for the negative category in the Chilean sample. Also, for the Chilean sample, a higher correlation between valence and arousal was observed for men, showing that they perceive positive pictures as more exciting, when compared to women. For the negative category, the association between valence and arousal tended to be higher for women.

\section{FIGURE 2}

Affective space adopted by positive, neutral and negative pictures in women (left panel) and men (right panel). Correlations between arousal and valence for both positive and negative pictures are showed by upper and lower arrows within each panel, respectively
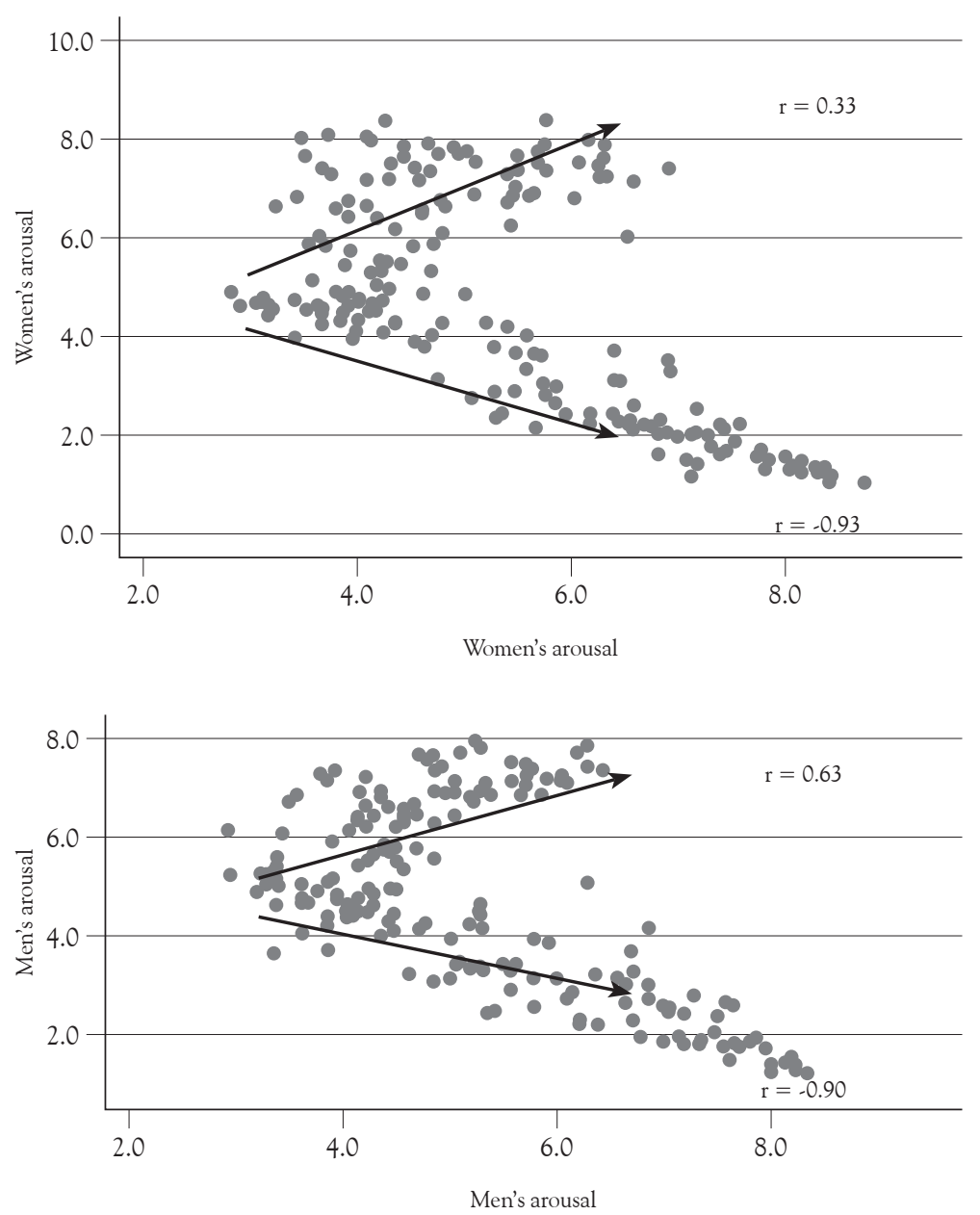

Source: Own work. 


\section{Discussion}

The IAPS has shown to be a reliable and valid method to assess affectivity in a variety of research, including psychiatric illness (e.g., Miltner et al., 2005; Quirk \& Strauss, 2001), cognitive neuroscience (Hot, Saito, Mandai, Kobayashi \& Sequeira, 2006; Junghöfer, Bradley, Elbert \& Lang, 2001; Schupp et al., 2006) and psychophysiology (Bradley et al., 2001a; 2001b), among many others. Also, validation measures of the IAPS have been obtained in different countries with an important level of consistency, pointing to the robustness of the bi-dimensional structure of affectivity (Davidson, 2003; Lang, 1995; Lang, et al., 1990). The present study was aimed to validate the IAPS in a Chilean sample in order to obtain a first account of the method in the local context, as well as to contribute to its cross-cultural validation.

The results show appropriate reliability of the selected pictures, indexed by high levels of internal consistencies for both the valence and arousal dimensions. The affective space that emerges follows the expected "boomerang" shape, confirming the fundamental affective structure of the motivational systems, as has been observed across the various validation studies (Bradley \& Lang, 2007; Grühn \& Scheibe, 2008; Moltó et al., 1999; Ribeiro et al., 2004, 2005; Verschuere et al., 2007; Vila et al., 2001). Also, the strong and negative relationship between arousal and valence reveals that negative pictures are perceived as more arousing than positive pictures.

An interesting finding involves the significant differences in arousal scores among the US and the Chilean data that emerged for the total correlation between valence and arousal ratings within each country, pointing to a higher association between valence and arousal in the Chilean sample. Also, the comparison of arousal scores between both countries shows that emotional pictures are appreciated as more arousing in the Chilean sample. Such discrepancies in the arousal ratings have been also seen in previous studies, such as those conducted in Spain (Moltó et al., 1999; Vila et al., 2001), Germany (Grühn \& Scheibe, 2008) and Brazil (La- saitis et al., 2008; Ribeiro et al., 2004, 2005). Those differences have been explained in two ways, first, in the Brazilian standardization of the IAPS a possible semantic and conceptual variation between languages and populations has been highlighted, which could result in a different understanding of what the arousal dimension means. On the other hand, Bradley and Lang (2007) have also noted the variability in the arousal ratings among countries, assuming that the IAPS can be sensitive to intercultural differences in emotion disposition, so it can reliably be used for detecting cross-cultural affective experience. Furthermore, at a theoretical level it can be noted that whereas both the appetitive and defensive systems behave in a more robust way, supported by the high consistency of findings across studies in the valence dimension, the arousal sensitivity can be more dependent on cultural aspects. This kind of explanation for the cross-cultural differences have also been stressed in the Spanish adaptation of the IAPS, assuming that the higher arousal scores for the Latin samples are coherent with the cultural stereotypes of emotional expressivity.

Another theoretical aspect concerning the readiness of each motivational system to be activated is confirmed by the finding that the valence-arousal correlations are stronger in magnitude for the negative than for the positive picture categories. That means that the association between valence and arousal is greater for aversive information, which could be owed to the lack of stimuli that fulfill the negative low arousing portion of the affective space, as has been stated by Bradley and Lang (2007). Another possibility is to assume that there is an adaptive value in having a higher sensitivity to aversive information in relation to pleasant contents, which could explain this "negativity bias". In any case, the stronger association between negative valence and arousal is well replicated across studies (Bradley \& Lang, 2007; Grühn \& Scheibe, 2008; Moltó et al., 1999; Ribeiro et al., 2004, 2005; Verschuere et al., 2007; Vila et al., 2001), becoming a robust result across countries.

Sex differences in the Chilean sample show that men are more excited than women by positive 
pictures, whereas women tend to be more aroused than men by negative stimuli. This finding is in line with previous evidence, both in the US (Bradley et al., 2001b), and Spanish studies (Moltó et al., 1999; Vila et al., 2001), although it has not been seen in all the studies wherein sex differences were analyzed (e.g. Ribeiro et al., 2004). However, sex differences have been found in studies where electrophysiological variables were assessed, allowing a higher reliability of the differences between men and women, as those parameters are more robust and less susceptible of variations derived from subjective appraisal. Bradley et al. (2001b) have seen that facial EMG, skin conductance and heart rate have distinct activation patterns by emotional stimuli in both men and women, with women showing a higher electrophysiological reactivity in all parameters in face of unpleasant material, and men being more reactive to pleasant pictures, particularly erotica. Thus, our results are also consistent with this more reliable assessment of sex dependent reactivity to emotional pictures.

Some limitations of the study may arise from the intentional extraction of the sample and the reduced participation of men, affecting the generalization of the present findings. We encourage further studies to address those restrictions and also to incorporate populations with diverse characteristics that may affect emotional responding, as clinical populations or different age ranges, in order to extend the validity of the IAPS.

In conclusion, the Chilean adaptation of the IAPS show consistent results with previous evidence, particularly with the US validation study with which comparative statistical analysis was performed, adding support to the validity of the methodology and the system's picture content. Variations in the procedure of selection and administration of pictures seem to be minor in face to the robustness of results obtained across countries wherein the IAPS has been validated. The main variations are found in the arousal dimension, with valence results tending to be more consistent between studies, pointing to possible cross-cultural variations in arousal sensitivity.

\section{References}

Amrhein, C., Mülberger, A., Pauli, P. \& Wiedemann, G. (2004). Modulation of event-related brain potentials during affective picture processing: $\mathrm{A}$ complement to startle reflex and skin conductance response? International Journal of Psychophysiology, 54, 231-240.

Bradley, M., Codispoti, M., Cuthbert, B. \& Lang, P. (2001a). Emotion and Motivation I: Defensive and appetitive reactions in picture processing. Emotion, 3, 276-298.

Bradley, M., Codispoti, M., Sabatinelli, D. \& Lang, P. (2001b). Emotion and motivation: II. Sex differences in picture processing. Emotion, 1, 300-319.

Bradley, M. \& Lang, P. (2007). The International Affective Picture System (IAPS) in the study of emotion and attention. In J. A. Coan \& J. J. B. Allen (Eds.), Handbook of Emotion Elicitation and assessment (pp. 29-46). Oxford: Oxford University Press.

Carretie, L. A. (2001). Psicofisiología. Madrid: Pirámide.

Davidson, R. (2003). Affective neuroscience and psychophysiology: Toward a synthesis. Psychophysio$\log y, 40,655-665$.

Fanselow, M. S. (1994). Neural organization of the defensive behavior system responsible for fear. Psychonomic Bulletin E Review, 1, 429-438.

Grühn, D. \& Scheibe, S. (2008). Age-Related Differences in Valence and Arousal Ratings of Pictures from the International Affective Picture System (IAPS): Do ratings become more extreme with age? Behavioral Research Methods, 40, 512-521.

Hot, P., Saito, Y., Mandai, O., Kobayashi, T. \& Sequeira, H. (2006). An ERP investigation of emotional processing in European and Japanese individuals. Brain Research, 1122, 171-178.

Junghöfer, M., Bradley, M., Elbert, T. \& Lang, P. (2001). Fleeting images: A new look at early emotion discrimination. Psychophysiology, 38, 175-178.

Kapp, B., Frysinger, R., Gallagher, M. \& Haselton, J. (1979). Amygdala central nucleus lesions: Effect on heart rate conditioning in the rabbit. Physiology Behavior, 6, 1109-1117.

Lang, P. (1980). Behavioural treatment and bio-bahaviour assessment: Computer applications. In Keil, 
A. Bradley, M. Hauk, O. Rockstroh, B., T. Elbert \& Lang, P. (2002). Large-scale neural correlates of affective picture viewing. Psychophysiology, 39, 641-649.

Lang, P. (1995). The emotion probe. Studies of motivation and attention. American Psychologist, 50, 372-385.

Lang, P., Bradley, M. \& Cuthbert, B. (1990). Emotion, attention, and the startle reflex. Psychological Review, 97, 377-395.

Lang, P., Bradley, M. \& Cuthbert, B. (2005). Intermational affective picture system (IAPS): Affective ratings of pictures and instruction manual (Technical Report A-6). Gainesville, FL: University of Florida.

Lasaitis, C., Ribeiro, R. \& Bueno, O. (2008). Brazilian norms for the International Affective Picture System (IAPS). Comparison of the affective ratings for new stimuli between Brazilian and NorthAmerican subjects. Revista Brasileira de Psiquiatria, 57, 270-275.

LeDoux, J. (1990). Information flow from sensation to emotion plasticity in the neural computation of stimulus values. In M. Gabriel \& J. Moore (Eds.), Learning and computational neuroscience: Foundations of adaptive networks (pp. 3-52). Cambridge, MA: Bradford Books/MIT Press.

Miltner, W., Trippe, R., Krieschel, S., Gutberlet, I., Hecht, H. \& Weiss, T. (2005). Event-related brain potentials and affective responses to threat in spider/snake-phobic and non-phobic subjects. International Journal of Psychophysiology, 57, 43-52.

Moltó, J., Montañés, S., Segarra, P., Pastor, M., Tormo, M., Ramírez, I. et al. (1999). Un nuevo método para el estudio experimental de las emociones: El "International Affective Picture System" (IAPS). Adaptación española. Revista de Psicología General y Aplicada, 52, 55-87.
Oloffsson, J., Nordin, S., Sequeira, H. \& Polich, J. (2008). Affective picture processing: An integrative review of ERP findings. Biological Psychology, 77, 247-265.

Palomba, D., Sarlo, M., Angrilli, A., Mini, A. \& Stegagno, L. (2000). Cardiac responses associated with affective processing of unpleasant film stimuli. International Journal of Psychophysiology, 36, 45-57.

Quirk, S. W. \& Strauss, M. E. (2001). Visual exploration of emotion eliciting images by patients with schizophrenia. Journal of Nervous Mental Disorders, 189, 757-765.

Ribeiro, R., Pompéia, S. \& Bueno, O. (2004). Normas brasileiras para o International Affective Picture System (IAPS): comunicação breve. Revista Brasileira de Psiquiatria, 26, 190-194.

Ribeiro, R., Pompéia, S. \& Bueno, O. (2005). Comparison of Brazilian and American norms for the International Affective Picture System (IAPS). Revista Brasileira de Psiquiatria, 27, 208-215.

Schupp, H., Cuthbert, B., Bradley, M., Birbaumer, N. \& Lang, P. (1997). Probe P3 and blinks: Two measures of affective strartle modulation. Psychophysiology, 34, 1-6.

Schupp, H., Stockburger, J., Codispoti, M., Junghöfer, M., Weike, A. \& Hamm, A. (2006). Stimulus novelty and emotion perception: The near absence of habituation in the visual cortex. Cognitive Neuroscience and Neuropsychology, 17, 1107-1110.

Verschuere, B., Crombez, G. \& Koster, E. (2007). The international affective picture system: A cross cultural validation study. Belgium: Ghent University.

Vila, J., Sánchez, M., Ramírez, I., Fernández, C., Cobos, P., Rodríguez, S. et al. (2001). El Sistema General de Imágenes Afectivas (IAPS): adaptación española. Segunda Parte. Revista de Psicología General y Aplicada, 54, 635-657. 


\section{Appendix 1}

\begin{tabular}{|c|c|c|c|c|c|c|c|c|c|c|c|}
\hline \multirow[t]{2}{*}{ IAPS slide \# } & \multirow[t]{2}{*}{ Description } & \multicolumn{2}{|c|}{ Valence } & \multicolumn{2}{|c|}{ Arousal } & \multirow[t]{2}{*}{ IAPS slide \# } & \multirow[t]{2}{*}{ Description } & \multicolumn{2}{|c|}{ Valence } & \multicolumn{2}{|c|}{ Arousal } \\
\hline & & Mean & $\mathrm{SD}$ & Mean & $\mathrm{SD}$ & & & Mean & $\mathrm{SD}$ & Mean & SD \\
\hline 2000 & Adult & 5.89 & 1.44 & 4.30 & 2.08 & 2455 & Sad Girls & 3.40 & 1.72 & 5.63 & 2.10 \\
\hline 2005 & $\begin{array}{l}\text { Attractive } \\
\text { man }\end{array}$ & 6.39 & 1.35 & 4.92 & 2.21 & 2480 & Elderly & 4.55 & 1.67 & 4.69 & 2.26 \\
\hline 2010 & Adult & 5.80 & 1.46 & 4.45 & 1.98 & 2490 & Man & 3.13 & 1.41 & 5.37 & 1.98 \\
\hline 2037 & Woman & 7.68 & 1.08 & 4.83 & 2.48 & 2491 & Sick Man & 4.05 & 1.61 & 4.19 & 1.91 \\
\hline 2053 & Baby & 1.86 & 1.66 & 7.26 & 2.04 & 2493 & Neutral male & 4.38 & 1.22 & 4.24 & 2.01 \\
\hline 2070 & Baby & 7.51 & 1.47 & 6.17 & 2.41 & 2495 & Man & 4.80 & 1.35 & 3.98 & 1.84 \\
\hline 2071 & Baby & 7.72 & 1.30 & 5.39 & 2.59 & 2500 & Man & 6.35 & 1.51 & 4.38 & 2.23 \\
\hline 2095 & Toddler & 1.14 & 0.35 & 8.21 & 1.13 & 2512 & Man & 4.74 & 1.03 & 4.07 & 1.92 \\
\hline 2100 & Angryface & 3.30 & 1.36 & 4.92 & 1.93 & 2515 & Harvest & 6.48 & 1.58 & 3.97 & 2.06 \\
\hline 2102 & Neutral Man & 5.22 & 1.43 & 3.80 & 1.89 & 2520 & Elderly Man & 3.80 & 1.81 & 5.04 & 2.11 \\
\hline 2104 & $\begin{array}{l}\text { Neutral wo- } \\
\text { man }\end{array}$ & 4.44 & 1.30 & 3.95 & 1.94 & 2530 & Couple & 7.65 & 1.51 & 5.50 & 2.44 \\
\hline 2120 & Angryface & 2.42 & 1.16 & 6.33 & 2.11 & 2550 & Couple & 7.59 & 1.17 & 5.39 & 2.38 \\
\hline 2130 & Woman & 2.49 & 1.40 & 6.65 & 2.07 & 2570 & Man & 4.88 & 1.26 & 4.04 & 1.98 \\
\hline 2141 & Grievingfem & 2.25 & 1.33 & 6.70 & 1.82 & 2579 & Bakers & 5.37 & 1.40 & 4.39 & 1.81 \\
\hline 2150 & Baby & 7.02 & 1.77 & 4.36 & 2.68 & 2590 & $\begin{array}{l}\text { Elderly Wo- } \\
\text { man }\end{array}$ & 3.54 & 1.50 & 5.57 & 2.03 \\
\hline 2152 & Mother & 7.33 & 1.53 & 5.82 & 2.62 & 2594 & City & 6.11 & 1.85 & 4.47 & 1.96 \\
\hline 2165 & Father & 7.14 & 1.74 & 4.28 & 2.65 & 2598 & Family & 6.95 & 1.36 & 4.91 & 2.20 \\
\hline 2190 & Man & 4.67 & 1.21 & 4.05 & 2.07 & 2600 & $\mathrm{Be}$ & 5.03 & 1.96 & 4.02 & 1.70 \\
\hline 2200 & Neutral face & 4.41 & 1.17 & 4.02 & 1.87 & 2630 & Male & 4.57 & 1.83 & 4.04 & 1.99 \\
\hline 2205 & Hospital & 2.61 & 1.69 & 5.25 & 2.49 & 2650 & Boy & 6.23 & 1.78 & 4.46 & 2.19 \\
\hline 2208 & Bride & 6.85 & 1.27 & 5.63 & 1.99 & 2655 & Child & 7.54 & 1.51 & 4.73 & 2.84 \\
\hline 2209 & Bride & 6.90 & 1.59 & 5.34 & 2.22 & 2683 & War & 1.73 & 1.08 & 7.73 & 1.72 \\
\hline 2210 & Neutral face & 4.47 & 1.45 & 4.74 & 1.96 & 2691 & Riot & 3.05 & 1.86 & 6.63 & 1.75 \\
\hline 2214 & Neutral man & 4.90 & 1.10 & 3.89 & 1.76 & 2700 & Woman & 2.89 & 1.26 & 5.42 & 2.18 \\
\hline 2215 & Neutral man & 4.67 & 1.04 & 3.73 & 1.88 & 2703 & Sad children & 1.39 & 0.73 & 7.83 & 1.57 \\
\hline 2216 & Children & 6.55 & 1.45 & 4.98 & 2.07 & 2704 & Soldiers & 3.71 & 2.27 & 6.89 & 1.83 \\
\hline 2221 & Judge & 3.78 & 1.35 & 4.22 & 2.13 & 2710 & Drug Addict & 3.08 & 1.70 & 6.16 & 2.21 \\
\hline 2230 & Sad face & 4.11 & 0.99 & 4.47 & 1.96 & 2718 & Drug addict & 1.90 & 1.28 & 7.30 & 1.54 \\
\hline
\end{tabular}




\begin{tabular}{|c|c|c|c|c|c|c|c|c|c|c|c|}
\hline \multirow[t]{2}{*}{ IAPS slide \# } & \multirow[t]{2}{*}{ Description } & \multicolumn{2}{|c|}{ Valence } & \multicolumn{2}{|c|}{ Arousal } & \multirow[t]{2}{*}{ IAPS slide \# } & \multirow[t]{2}{*}{ Description } & \multicolumn{2}{|c|}{ Valence } & \multicolumn{2}{|c|}{ Arousal } \\
\hline & & Mean & $\mathrm{SD}$ & Mean & $\mathrm{SD}$ & & & Mean & $\mathrm{SD}$ & Mean & SD \\
\hline 2272 & Lonely Boy & 4.25 & 2.09 & 5.43 & 2.03 & 2749 & Smoking & 5.21 & 1.84 & 3.46 & 1.82 \\
\hline 2276 & Girl & 2.49 & 1.29 & 5.86 & 2.14 & 2750 & Bum & 2.38 & 1.52 & 6.40 & 2.40 \\
\hline 2278 & Kids & 2.57 & 1.30 & 6.35 & 2.10 & 2751 & $\begin{array}{l}\text { Drunk Dri- } \\
\text { vng }\end{array}$ & 3.80 & 1.93 & 6.73 & 1.93 \\
\hline 2280 & Boy & 4.39 & 1.09 & 4.29 & 1.87 & 2753 & Alcoholic & 3.37 & 1.82 & 5.38 & 2.05 \\
\hline 2303 & Children & 7.35 & 1.33 & 4.77 & 2.42 & 2800 & Sadchild & 1.44 & 0.78 & 8.19 & 1.06 \\
\hline 2304 & Girl & 6.70 & 1.74 & 4.25 & 2.31 & 2810 & Boy & 3.61 & 1.70 & 6.80 & 1.78 \\
\hline 2306 & Boy & 7.69 & 1.52 & 4.84 & 2.60 & 2850 & Tourist & 4.91 & 1.41 & 3.64 & 1.99 \\
\hline 2310 & Mother & 7.26 & 1.27 & 3.53 & 2.21 & 2870 & Teenager & 6.08 & 1.93 & 4.25 & 1.92 \\
\hline 2311 & Mother & 7.17 & 1.76 & 5.40 & 2.11 & 2900 & Cryingboy & 2.21 & 1.30 & 6.28 & 1.85 \\
\hline 2312 & Mother & 3.16 & 1.69 & 5.65 & 1.98 & 2900.2 & Smiling girl & 6.38 & 1.37 & 4.73 & 1.78 \\
\hline 2320 & Girl & 5.67 & 1.52 & 4.10 & 1.84 & 3016 & Mutilation & 1.31 & 0.64 & 8.31 & 0.99 \\
\hline 2331 & Chef & 6.41 & 2.06 & 4.18 & 2.47 & 3030 & Mutilation & 1.20 & 0.42 & 8.37 & 1.15 \\
\hline 2332 & Family & 7.70 & 1.58 & 4.00 & 2.48 & 3180 & Battered fem & 1.68 & 1.09 & 7.47 & 1.94 \\
\hline 2340 & Family & 7.70 & 1.42 & 6.22 & 2.48 & 3181 & Battered fem & 1.25 & 0.84 & 8.35 & 1.16 \\
\hline 2341 & Children & 7.14 & 1.58 & 4.11 & 2.34 & 3220 & Hospital & 2.30 & 1.36 & 6.82 & 2.03 \\
\hline 2344 & Children & 7.37 & 1.53 & 4.65 & 2.39 & 3230 & Dying Man & 1.54 & 0.75 & 6.95 & 2.17 \\
\hline 2345 & Children & 7.59 & 1.45 & 5.53 & 2.15 & 3280 & Dental exam & 3.04 & 1.62 & 5.73 & 2.36 \\
\hline 2346 & Children & 7.34 & 1.58 & 4.69 & 2.74 & 3300 & $\begin{array}{l}\text { Disabled } \\
\text { child }\end{array}$ & 2.44 & 1.10 & 5.80 & 2.07 \\
\hline 2357 & Man & 6.38 & 1.72 & 3.08 & 2.04 & 3301 & Injured child & 1.27 & 0.56 & 8.19 & 1.25 \\
\hline 2358 & Family & 5.94 & 1.57 & 4.01 & 1.93 & 3350 & Infant & 1.55 & 0.98 & 8.06 & 1.36 \\
\hline 2360 & Family & 7.65 & 1.27 & 3.62 & 2.55 & 3500 & Attack & 1.62 & 0.84 & 7.83 & 1.90 \\
\hline 2381 & Girl & 5.49 & 1.53 & 4.06 & 1.96 & 3530 & Attack & 1.38 & 0.73 & 8.21 & 1.05 \\
\hline 2387 & Kids & 6.87 & 1.52 & 4.57 & 2.02 & 3550 & Injury & 1.59 & 0.86 & 7.87 & 1.41 \\
\hline 2391 & Boy & 5.87 & 1.71 & 4.37 & 2.11 & 4141 & Erotic female & 5.75 & 2.05 & 5.42 & 2.27 \\
\hline 2395 & Family & 7.10 & 1.21 & 3.95 & 1.98 & 4142 & Erotic female & 5.44 & 2.19 & 4.98 & 2.45 \\
\hline 2398 & Boat & 7.06 & 1.49 & 3.58 & 2.16 & 4150 & $\begin{array}{l}\text { Attractive } \\
\text { fem }\end{array}$ & 6.05 & 1.42 & 4.65 & 2.24 \\
\hline 2399 & Woman & 3.04 & 1.19 & 5.13 & 1.94 & 4180 & Erotic female & 5.61 & 2.28 & 5.30 & 2.36 \\
\hline 2410 & Boy & 3.60 & 1.77 & 5.17 & 2.02 & 4220 & Erotic female & 6.42 & 1.59 & 5.08 & 2.26 \\
\hline 2435 & Mom/Son & 5.23 & 1.08 & 4.35 & 2.07 & 4535 & Weight-lifter & 4.87 & 1.72 & 4.58 & 1.92 \\
\hline
\end{tabular}


Michele Dufey, Ana María Fernández, Rocío Mayol

\begin{tabular}{|c|c|c|c|c|c|c|c|c|c|c|c|}
\hline \multirow[t]{2}{*}{ IAPS slide \# } & \multirow[t]{2}{*}{ Description } & \multicolumn{2}{|c|}{ Valence } & \multicolumn{2}{|c|}{ Arousal } & \multirow[t]{2}{*}{ IAPS slide \# } & \multirow[t]{2}{*}{ Description } & \multicolumn{2}{|c|}{ Valence } & \multicolumn{2}{|c|}{ Arousal } \\
\hline & & Mean & SD & Mean & SD & & & Mean & SD & Mean & SD \\
\hline 2440 & Neutral girl & 4.26 & 1.08 & 4.04 & 2.03 & 4537 & $\begin{array}{l}\text { Attractive } \\
\text { man }\end{array}$ & 5.31 & 1.78 & 4.64 & 2.12 \\
\hline 2441 & Neutral girl & 4.26 & 1.39 & 5.19 & 1.87 & 4538 & Erotic male & 5.74 & 1.90 & 4.87 & 2.25 \\
\hline 2442 & Drying Hair & 6.61 & 1.43 & 4.37 & 2.32 & 4574 & $\begin{array}{l}\text { Attractive } \\
\text { man }\end{array}$ & 7.11 & 1.49 & 5.36 & 2.24 \\
\hline 4598 & Romance & 3.93 & 2.36 & 5.85 & 2.21 & 7030 & Iron & 4.43 & 1.19 & 3.96 & 2.28 \\
\hline 4599 & Romance & 7.22 & 1.51 & 4.62 & 2.63 & 7035 & Mug & 5.23 & 1.28 & 3.58 & 2.20 \\
\hline 4603 & Romance & 6.53 & 1.49 & 4.93 & 1.99 & 7040 & Dust pan & 4.00 & 1.34 & 3.51 & 2.17 \\
\hline 4607 & Erotic couple & 7.42 & 1.70 & 6.38 & 2.12 & 7056 & Tool & 4.52 & 1.20 & 3.26 & 1.90 \\
\hline 4608 & Erotic couple & 7.24 & 1.35 & 6.02 & 2.16 & 7057 & Coffee cup & 5.23 & 1.68 & 4.35 & 2.05 \\
\hline 4611 & Erotic couple & 7.55 & 1.56 & 5.55 & 2.36 & 7080 & Fork & 4.68 & 1.06 & 3.35 & 2.18 \\
\hline 4614 & Romance & 6.48 & 1.37 & 4.44 & 2.25 & 7090 & Book & 5.22 & 1.25 & 3.80 & 2.37 \\
\hline 4617 & Erotic female & 6.66 & 1.26 & 4.99 & 2.05 & 7100 & Fire hydrant & 4.86 & 1.23 & 3.78 & 2.15 \\
\hline 4621 & $\begin{array}{l}\text { Embarasse- } \\
\text { ment }\end{array}$ & 2.87 & 1.55 & 6.58 & 2.06 & 7150 & Umbrella & 4.97 & 1.10 & 3.77 & 2.05 \\
\hline 4623 & Romance & 7.22 & 1.42 & 5.32 & 2.22 & 7170 & Light-bulb & 4.56 & 1.38 & 4.11 & 2.01 \\
\hline 4626 & Wedding & 6.85 & 1.69 & 3.93 & 2.48 & 7175 & Lamp & 4.93 & 1.07 & 2.92 & 1.83 \\
\hline 4641 & Romance & 7.03 & 1.57 & 4.37 & 2.55 & 7190 & Clock & 4.69 & 1.14 & 4.22 & 2.41 \\
\hline 4660 & Erotic couple & 6.82 & 1.92 & 5.94 & 2.18 & 7211 & Clock & 4.42 & 1.32 & 3.85 & 2.08 \\
\hline 4687 & Erotic couple & 6.53 & 1.99 & 6.11 & 1.88 & 7217 & Clothes rack & 4.65 & 1.15 & 3.41 & 1.96 \\
\hline 4689 & Erotic couple & 7.15 & 1.61 & 6.18 & 1.93 & 7235 & Chair & 4.78 & 1.29 & 3.3 & 2.11 \\
\hline 5410 & Violonist & 6.60 & 1.92 & 4.30 & 2.55 & 7325 & Watermelon & 7.86 & 1.16 & 6.02 & 2.53 \\
\hline 5875 & Bicyclist & 6.81 & 1.80 & 3.89 & 2.20 & 7550 & Office & 3.79 & 1.51 & 3.65 & 2.20 \\
\hline 6010 & Jail & 2.83 & 1.47 & 5.30 & 2.36 & 8120 & Athlete & 7.45 & 1.36 & 4.49 & 2.60 \\
\hline 6212 & Soldier & 1.50 & 1.07 & 8.17 & 1.31 & 8461 & Happy Teens & 7.31 & 1.44 & 5.02 & 2.61 \\
\hline 6213 & Terrorist & 2.38 & 1.25 & 6.87 & 1.93 & 8490 & $\begin{array}{l}\text { Roller Coas- } \\
\text { ter }\end{array}$ & 7.38 & 1.76 & 6.67 & 2.16 \\
\hline 6350 & Attack & 1.86 & 1.11 & 7.46 & 1.76 & 8496 & Water Slide & 7.90 & 1.61 & 5.34 & 2.86 \\
\hline 6540 & Attack & 2.33 & 1.85 & 7.38 & 1.86 & 9041 & Scared Child & 2.12 & 1.16 & 6.51 & 1.82 \\
\hline 6550 & Attack & 1.76 & 1.02 & 7.44 & 1.86 & 9050 & Plane Crash & 2.38 & 1.78 & 7.50 & 1.75 \\
\hline 6560 & Attack & 1.65 & 1.03 & 7.52 & 1.60 & 9070 & Boy & 4.42 & 2.21 & 5.34 & 2.42 \\
\hline 6562 & Attack & 3.24 & 1.27 & 5.28 & 1.99 & 9160 & Soldier & 2.66 & 1.49 & 6.93 & 1.82 \\
\hline 6570 & Suicide & 1.96 & 1.16 & 7.24 & 1.85 & 9190 & Woman & 3.41 & 1.52 & 5.89 & 1.80 \\
\hline
\end{tabular}


AdDING SUPPORT TO CROSS-CULTURAL EMOTIONAL ASSESSMENT

\begin{tabular}{clllllllllll}
\hline IAPS slide \# & Description & \multicolumn{2}{c}{ Valence } & \multicolumn{2}{c}{ Arousal } & IAPS slide \# & Description & \multicolumn{2}{c}{ Valence } & \multicolumn{2}{c}{ Arousal } \\
\hline & & Mean & SD & Mean & SD & & & Mean & SD & Mean & SD \\
\hline 6821 & Gang & 2.07 & 1.43 & 7.82 & 1.86 & 9210 & Rain & 5.25 & 2.27 & 4.46 & 2.01 \\
6825 & Military & 2.45 & 1.29 & 6.72 & 1.93 & 9220 & Cemetery & 2.44 & 1.38 & 5.35 & 2.10 \\
6838 & Police & 2.37 & 1.31 & 7.22 & 1.84 & 9421 & Soldier & 1.84 & 1.04 & 6.69 & 2.10 \\
7002 & Towel & 4.79 & 1.01 & 3.40 & 2.06 & 9429 & Assault & 2.06 & 1.15 & 7.40 & 1.86 \\
7009 & Mug & 5.14 & 1.13 & 3.09 & 1.91 & 9520 & Kids & 3.76 & 1.95 & 5.87 & 1.93 \\
7010 & Basket & 4.90 & 1.24 & 3.37 & 2.12 & 9530 & Boys & 2.53 & 1.63 & 6.76 & 2.00 \\
7020 & Fan & 4.76 & 1.29 & 3.40 & 2.20 & 9582 & Dental Exam & 2.14 & 1.47 & 7.18 & 1.94 \\
7025 & Stool & 5.02 & 0.96 & 3.20 & 1.96 & 9592 & Injection & 2.76 & 1.71 & 6.59 & 2.20 \\
\hline
\end{tabular}


